\title{
EM MEIO AO DIVERSO E AO PLURAL: SAUDADES DE NOVA YORK E RELATO DE UM CERTO ORIENTE ${ }^{1}$
}

\author{
Silvio Renato Jorge \\ Universidade Federal Fluminense
}

\begin{abstract}
Como podemos conceber ou imaginar a identidade, a diferença e o pertencimento, após a diáspora? Já que a “identidade cultural” carrega consigo tantos traços de unidade essencial, unicidade primordial, indivisibilidade e mesmice, como devemos "pensar" as identidades inscritas nas relações de poder, construídas pela diferença, disjuntura?
\end{abstract}

Stuart Hall

As questões aqui levantadas por Stuart Hall (HALL, 2003, p.28), apesar de referirem-se a um contexto específico - a diáspora dos emigrantes caribenhos que vivem no Reino Unido -, conduzem-nos a toda uma reflexão acerca das possibilidades de relacionarmos os conceitos de identidade e de pertencimento a termos mais flexíveis, capazes de dar conta das múltiplas relações culturais passíveis de se estabelecerem no mundo contemporâneo. Vivemos em uma época na qual a relativização do tempo e do espaço nos conduz a um novo modo de perceber a existência e a idéia de globalização cultural nos impõe a necessidade de refletir acerca do valor que poderíamos atribuir à fronteira, vista não mais apenas a partir daquilo que seu sentido pode indicar de separação, mas também no que ele pode informar como elemento de interação, de diálogo. Ou seja: com o fim dos Novecentos e o

\footnotetext{
1 Este texto reúne, com algumas alterações, idéias discutidas em mesa-redonda no XIX Encontro
} da ABRAPLIP, em Curitiba, outubro de 2003. 
raiar de um novo século, torna-se premente a revisão das fórmulas tradicionais de se compreender a nação e, conseqüentemente, a literatura capaz de com ela dialogar. Este texto pretende, pois, ensaiar uma leitura de determinados aspectos que permeiam a produção literária em língua portuguesa a partir dos anos noventa, tomando como parâmetro a escrita de dois autores, o português Pedro Paixão e o brasileiro Milton Hatoum, autores estes que investem, através de seus textos, na tentativa de compreensão de possíveis diálogos culturais e na dissolução de essencialismos anacrônicos que permeiam muito do que já foi dito acerca daqueles que optam pela experiência da fronteira como local privilegiado do viver. Lembro, ainda, e apenas a título de uma segunda e tardia epígrafe, dos versos de um outro escritor português, Jorge de Sena (1989, p.75), ao afirmar que:

Com pátrias nos compram e nos vendem, à falta de pátrias que se vendam suficientemente caras para haver vergonha de não pertencer a elas. Nem eu, nem o Minotauro, teremos nenhuma pátria. Apenas o café, aromático e bem forte, não da Arábia ou do Brasil, da Fedecam, ou de Angola, ou parte alguma. Mas café contudo e que eu, com filial ternura, verei escorrer-lhe do queixo de boi até aos joelhos de homem que não sabe de quem herdou, se do pai, se da mãe, os cornos retorcidos que ornam a nobre fronte anterior a Atenas, e, quem sabe, à Palestina, e outros lugares turísticos, imensamente patrióticos.

Recupero aqui a poesia de Sena, talvez, para nós brasileiros, o mais representativo dos exilados portugueses, apenas para dar início a essa reflexão que pretende ressaltar a experiência de fronteira como um dos elementos significativos de nossa atual vivência. Não por acaso, Néstor García Canclini, em seu recente $A$ globalização imaginada, nos informa acerca do caráter fugidio daquilo que chamamos de globalização cultural, realçando a necessidade que mesmo os seus agentes sentem de descrevê-la por meio de narrações e metá- 
foras. Além disso, informa que "as migrações, as fronteiras permeáveis e as viagens falam, em seus estranhamentos, daquilo que a globalização tem de fratura e segregação" e que "também por isso irrompem narrativas e metáforas nos relatos de migrantes e exilados" (CANCLINI, 2003, p.9). Deste modo, não estaríamos errados ao afirmarmos que torna-se cada vez mais clara a necessidade de repensarmos a globalização cultural como um movimento de difícil apreensão, e que não pode ser lido pelo mero viés da oposição entre o local e o global. É certo que a complexidade das trocas culturais implica um processo constante de transformação e de adaptação, responsável por nos levar a crer que, mais do que apontar para uma revisão de questões identitárias materializadas a partir do isolamento, os atuais estudos acerca dessa questão devem realçar o esforço para se compreender o que é possível construir com o outro, como é possível lidar com a desigualdade, com o heterogêneo e o diferente. Se é imperativo revermos criticamente o modo como os meios de comunicação de massa muitas vezes recorrem a um imaginário de matizes pretensamente universais, cuja origem bem conhecemos, e difundem, de forma quase programática, valores aparentemente distintos daqueles que imaginamos como nossos, não se faz menos significativa a premência de revermos nossas certezas locais, deixando de lado os estereótipos através dos quais observávamos o outro, que passa a se tornar mais presente. É importante notar que esta convivência, estabelecida a partir de parâmetros distintos daqueles gerados pela colonização e pelo colonialismo - ao menos em tese -, se quer menos incompreensiva, mais dialogante. Não é demais citar mais uma vez Canclini, quando afirma:

Ao deslocar o debate sobre a globalização da questão da identidade para a dos desencontros entre políticas de integração supranacional e comportamentos cidadãos, negamo-nos a reduzi-lo à oposição global/ local. Tentamos situá-lo na recomposição geral do abstrato e do concreto na vida contemporânea e na formação de novas mediações entre os dois extremos. Mais do que contrapor identidades essencializadas à globalização, trata-se de indagar se é possível instituir sujeitos em estruturas sociais ampliadas. (CANCLINI, 2003, p.28)

Espaço de mediação e interlocução, a fronteira - mais do que a física, a metafórica - surge como lugar privilegiado para descortinar a circulação 
de mensagens, expressando em um plano simbólico os processos de intercâmbio aí estabelecidos. Daí, a importância de compreendermos o caráter questionador e, ao mesmo tempo, descritivo que a narrativa de viagem e as referências aos intercâmbios culturais gerados pela emigração adquirem em um mundo para o qual o trânsito entre fronteiras - econômicas, mas também culturais, não esqueçamos - se faz um dos pontos de partida para $o$ seu auto-conhecimento. Nesse sentido, gostaria de destacar um livro produzido pelo escritor português Pedro Paixão, exemplo das reflexões desenvolvidas pelo autor em seus últimos textos, em que se evidencia não apenas um profundo questionamento sobre o peso da existência no mundo contemporâneo, mas também o inevitável diálogo com novas e distintas realidades culturais. Se para escritores como José Saramago, António Lobo Antunes, Lídia Jorge e Olga Gonçalves - apenas para citar alguns dos que acompanharam o boom do romance português na década de oitenta, destacando-se pela qualidade com que souberam e sabem conduzir o processo de escrita como dizia, se para esses escritores repensar a pátria é uma vereda incontornável, para não dizer necessária mesmo, por estabelecer todo um processo de revisão da aventura imperialista de Portugal, além da crítica ao conservadorismo de sua sociedade, a escrita de Pedro Paixão parece iniciarse de um ponto em que, mais do que indagar acerca do passado, se faz necessário também compreender as novas relações sócio-culturais estabelecidas em nosso tempo, relações estas que parecem cobrar de cada um o bilhete de identidade, não para saber de onde se vem ou para onde se vai, mas para intuir quem se é. Creio ser possivel afirmar que seus textos partem de um vazio, vazio este que acentua a incomunicabilidade do indivíduo, a solidão em meio ao diverso e ao plural, para colocar em xeque qualquer possibilidade de identificação construída em termos fechados, definitivos. Por isso, é importante perceber como o material produzido por esse escritor se propõe a relativizar fronteiras, tanto estéticas quanto geográficas, para testemunhar encontros que desvanecem, muitas vezes, na própria possibilidade de sua ocorrência.

Em Saudades de Nova York, publicado em Portugal no ano de 2000, pela editora Cotovia, nos deparamos com a escrita de um diário que, desde seu início, se afirma como um não diário. $\mathrm{O}$ aviso que encontramos na portada do livro informa: 
O diário, e não é um diário, que aqui se torna público foi escrito precipitadamente. Como se a língua em que escrevo tivesse os dias contados. A ansiedade é o tom dominante. (...) A morte é a possibilidade do impossível, o que nos percorre é um estranho modo de vida. Como qualquer um, conhecemos o medo, o arrependimento, a falta. Como nenhum, somos quem somos, únicos e sós. O diário, e não é um diário, gostaria de ser quando muito o estilhaço de um espelho que se quebrou sem querer, contados os dias. (PAIXÃO, 2002, p.7)

É a partir dos estilhaços do espelho aí recolhidos, porém, que acompanhamos a trajetória daquele que nos narra uma vida em trânsito, marcada por um deambular constante, inicialmente transcorrido em Portugal - através de Foz do Douro, Porto, Lisboa e outros - para, logo a seguir, nos encaminhar a diversos espaços de uma Nova York que se quer sedutora e, ao mesmo tempo, inapreensível. Mesmo que as referências aos traços que separam os dois espaços permeiem diversas páginas do texto, é importante destacar o quanto a sua escrita irá transferi-las a um segundo plano, para privilegiar a inexorável solidão - a falta - a habitar o corpo daquele que escreve, igualando, em um certo sentido, as diversas cidades como espaços da ausência - não do outro, mas de si mesmo. Não seria falho afirmar que, mais do que indagar o que é ser português, o seu texto aponta para uma reflexão acerca do que pode ser construído a partir do diálogo com o outro, quando a diluição de fronteiras se faz inevitável.

Em um universo de referências em excesso, porém, os encontros, mesmo que sejam muitos, reiteram a percepção de uma impossibilidade, o retorno assustador a não se sentir capaz de encontrar algo que vá além da experiência do momento, ou melhor dizendo, da fugacidade de um existir fragmentário. Cito:

As pessoas falam sobre a cidade, repetem o nome da cidade, como se estivessem surpreendidas por estarem ali, por a cidade existir. De um momento para o outro tudo se pode desfazer. As pessoas estão apaixonadas pela cidade, não por pessoas. Ou então por pessoas que se encontram de passagem pela cidade. $\mathrm{O}$ poder de uma cidade sobre as almas. (PAIXÃO, 2002, p.49) 
A idéia da cidade como passagem é reforçada no texto através de sua estrutura fragmentada, como a de um mosaico, em que os dias são inscritos no diário por meio da percepção de pequenos e cotidianos detalhes, da percepção, diria, quase fotográfica de cenas que impressionam a voz narrativa e a levam à recuperação de traços da memória ou de imagens significativas do vivido. Nada mais sugestivo do que as inúmeras referências à fotografia presentes no texto - e também à narrativa fílmica - o que não impede, entretanto, uma lacuna impossível de se preencher, intransponível mesmo, que se materializa na imagem que tenta dizer-se, na fotografia a encenar-se através de uma outra linguagem, de um outro código. $\mathrm{O}$ olhar que busca apreender os sentidos só se constrói pela experiência metafórica e compartimentada de um instantâneo e, ultrapassando a procura por estabelecer redes de significação, há o enquadramento da cena, por si só, em um ímpeto descritivo que, mais uma vez, recupera a importância da narrativa cinematográfica como parâmetro a influenciar o seu modo de construção. Há, portanto, mais uma fronteira a manifestar-se e a se diluir no texto: a fronteira dos gêneros: a novela que se estrutura como diário, pretensamente autobiográfico, sem que o efetivamente seja, a dialogar com o descritivo e ao mesmo tempo metafórico do ensaio fotográfico e com a valorização da cena, própria do cinematográfico.

Resta ainda lembrar que, a corroborar a valorização da cena como elemento de significação, o texto recorre, algumas vezes, à apreensão da cidade a partir de seus ícones, como, por exemplo, no caso de Nova York, o táxi sempre presente, assinalando um olhar que se deixa conduzir sobre o espaço urbano e reforçando, por isso, a idéia de trânsito e de passagem. É significativa a presença de uma única frase como desfecho do texto, em que se lê: "Atirado para dentro de um táxi, o meu corpo" (PAIXÃO, 2002, p.94). É significativo também que o primeiro retrato de Nova York se faça no texto a partir do táxi que o narrador toma do aeroporto para Manhatan, conduzido por alguém que, como ele, também habita a fronteira:

O condutor de táxi, a quem peço para me sentar no banco da frente ao seu lado, é um americano nascido no Paquistão. Chegou há doze anos, vai fazer cinqüenta. Diz-me que freqüenta uma mesquita em Queens e sofreu um acidente que o tornou bastante mais velho do que é. Começa 
com $\mathrm{v}$ todas as palavras escritas com w. Veeping em vez de weeping. Está convencido de que o próximo confronto mundial começará numa das guerras entre o Paquistão e a Índia, porque a América, a Inglaterra e a Rússia não defendem a democracia no Caxemira que, muçulmano, quer ser livre e paquistanês. $\mathrm{O}$ centro do universo permanece onde nasceu. (PAIXÃO, 2002, p.34)

Se para seu personagem a sedução da memória ainda é capaz de configurar um centro único, em torno do qual as referências giram, para aquele que narra, viajante a compor em imagens um mundo que o indaga, essa certeza dilui-se - sem, contudo, findar - ao perceber o estilhaçamento da identidade causado por uma nova experiência do tempo e do espaço, da metrópole como confluência de muitas vidas e distintos olhares.

A trilha percorrida por Milton Hatoum em Relato de um certo oriente, seu primeiro romance, publicado em 1989, nos leva da metrópole cosmopolita para a Manaus dos emigrantes libaneses, buscando nas relações familiares o núcleo a partir do qual se podem observar os conflitos gerados pela interpenetração de culturas e de experiências distintas. O relato que encontramos já não se trata de um pretenso diário, como o de Saudades de Nova York, mas também se constrói a partir da memória. Nele, nos deparamos com uma mulher a retornar a Manaus em busca de reencontrar aquela que a criara, Emelie, uma cristã libanesa. No entanto, seu projeto aparentemente se desfaz ao descobri-la morta, após a sua chegada. Inicia-se, então, um outro trabalho, o de recuperar Emelie através da memória, não apenas a sua, mas também a de outros personagens que entrelaçaram seu percurso de forma significativa ao daquela família: o filho mais velho, Hakin, o único a aprender o árabe e que também irá se distanciar de todos, ao mudar-se para o sul; o alemão Dorner, amigo da família e fotógrafo; o marido de Emelie, recuperado, mesmo depois de morto, através da memória de Dorner, e Hindié Conceição, amiga sempre presente, a partilhar com a conterrânea a solidão da velhice. Muitas vozes a compor um mosaico, nem sempre ordenado, nem sempre claro naquilo que revela, mas sobretudo rico em pequenos detalhes de extrema significação. Não podemos esquecer, contudo, um outro elemento significativo na construção dessa escrita: ela também se quer um diálogo, estabelecido com o irmão distante, na busca de compartilhar o que, para a narradora, 
é um regresso ao mais íntimo, um regresso ao seu destino e daqueles que, com ela, habitaram sua cidade natal:

Não esqueci meu caderno de diário, e, na última hora, decidi trazer o gravador, fitas e todas as tuas cartas. Na última, ao saber que vinha para Manaus, pedias para que eu anotasse tudo o que fosse possível (...) (...) Gravei várias fitas, enchi de anotações uma dezena de cadernos, mas fui incapaz de ordenar coisa com coisa. Confesso que as tentativas foram inúmeras e todas exaustivas, mas ao final de cada passagem, de cada depoimento, tudo se embaralhava em desconexas constelações de episódios, rumores de todos os cantos, fatos medíocres, datas e dados em abundância. Quando conseguia organizar os episódios em desordem ou encadear vozes, então surgia uma lacuna onde habitavam o esquecimento e a hesitação: um espaço morto que minava a seqüência de idéias. (HATOUM, 2001, 165)

Como vemos, esse relato à deriva, consciente de suas lacunas, é um relato que aponta para a memória e para a cidade - tempo e espaço - como elementos entrelaçados, construindo-se um a partir do outro, em uma complexa viagem “onde - no dizer de Davi Arrigucci Jr. - o destino do indivíduo se enlaça ao do grupo familiar na busca de si mesmo e do outro" (ARRIGUCCI JR., apud HATOUM, 2001, orelha). A viagem da memória, contudo, aponta também para a experiência concreta daqueles que, emigrantes ou seus descendentes, vivenciam em Manaus um espaço de fronteira em que, para além do confronto entre a cidade a floresta, percebemos a confluência de diversas línguas e de práticas que colocam em diálogo culturas distintas. São inúmeros os exemplos que dão conta desses diálogos: a religiosidade cristã de Emelie a conviver com a do marido muçulmano; a freqüência, em sua casa, de vizinhos das mais diversas nacionalidades; a mistura de aromas e sabores que detectamos no universo narrado: ao lado do odor de fumo produzido pelo narguilé e do aroma do hortelã, temos a referência ao cheiro do jasmim e das frutas tropicais. Cabe aqui, porém, enfatizar dois deles: o primeiro se refere ao encontro de Hakim com a língua árabe, quando vemos aguçar-se a sua consciência de habitar um espaço múltiplo, repleto de referências outras que aos poucos se revelam. São dele as palavras: 
Desde então, cresceu em mim um fascínio, uma curiosidade desmesurada pelas três linhas rabiscadas por Emilie e pela voz de meu pai. Já estava me habituando àquela fal estranha, mas por algum tempo pensei tratarse de uma linguagem só falada pelos mais idosos; ou seja, pensava que os adultos não falavam como as crianças. Aos poucos me dei conta de que eles gesticulavam mais ao falar naquele idioma, e houve casos em que intuí idéias através de gestos. (HATOUM, 2001, p.49)

Ou ainda:

Desde pequeno convivi com um idioma na escola e nas ruas da cidade, e com outro na Parisiense. E às vezes tinha a impressão de viver vidas distintas. Sabia que tinha sido eleito o interlocutor número um entre os filhos de Emilie: por Ter vindo ao mundo antes que os outros? Por encontrar-me ainda muito próximo às suas lembranças, ao seu mundo ancestral onde tudo ou quase tudo girava ao redor de Trípoli, das montanhas, dos cedros, das figueiras e parreiras, dos carneiros, Junieh e Ebrin? (HATOUM, 2001, p.52)

É através do contato com as duas línguas que Hakin aguça a sua percepção de habitar um universo familiar marcado pela pluralidade. Nele, não encontramos apenas falares que se multiplicam ou religiões a se manifestarem como espaço de enfrentamento e, ao mesmo tempo, de convivência. Há também ali, mesmo quando percebemos a afirmação de inúmeras tradições, um trânsito pelo diverso que permitirá a Emelie dialogar com a floresta e com suas tradições, mesmo sem nunca lá ter estado. É o caso da relação que estabelece com Lobato Naturidade, também conhecido por Tacumã, o índio responsável por encontrar o corpo de seu irmão morto e apelidado por Dorner de o "Príncipe da Magia Branca”. São, mais uma vez, as palavras de Hakin a nos dizer que: "Emilie tratava-o com um respeito que aspirava à veneração; raramente aparecia em casa, mas bastava pisar na soleira da porta para que toda a vizinhança se inteirasse de que na família havia um doente." (HATOUM, 2001, p.93). Compreendendo os mistérios que circundam a cidade, transformando, mesmo, seu quintal em parte da floresta que só vislumbrou, esta mulher libanesa conhecida por nós apenas através de outros olhares - e olhares nem sempre capazes de desvelar seus segredos - 
nos remete, mais uma vez, às dúvidas encetadas por Stuart Hall ao perceber a dificuldade de definir a identidade em termos de unidade e de indivisibilidade. Povoada por inúmeras faces, como o romance que a apresenta, parece nos convidar a novas reflexões sobre as fronteiras múltiplas em que também habitamos, estejamos em Nova York, Manaus ou mesmo aqui, ao trazermos à baila o estrangeiro que existe dentro de cada um de nós, brasileiros.

\section{BIBLIOGRAFIA}

CANCLINI, Néstor García. A globalização imaginada. Trad. Sérgio Molina. São Paulo: Iluminuras, 2003.

HALL, Stuart. Da diáspora: identidades e mediações culturais. Org. Liv Sovik. Trads. Adelaine La Guardia Resende et alii. Belo Horizonte: EdUFMG, 2003. HATOUM, Milton. Relato de um certo oriente. 2 ed. São Paulo: Cia das Letras, 2001.

PAIXÃO, Pedro. Onze noites em Jerusalém e dez poemas de Moche Benarroch. Lisboa: Cotovia, 2002. . Pedro. Portokioto: nuvens à deriva. 2 ed. Lisboa: Cotovia, 2001. . Pedro. Saudades de Nova York. Rio de Janeiro: 7 Letras, 2002.

SENA, Jorge de. Poesia III (Peregrinatio ad loca infecta; Exorcismos; Camões dirige-se aos seus contemporâneos; Conheço o sal e outros poemas; Sobre esta praia). Lisboa: Edições 70, 1989. 